\title{
Molecular studies on cyanobacterial diversity in lichen symbioses
}

\author{
Jouko Rikkinen' \\ I University of Helsinki, Department of Biosciences, P.O.Box 65, Helsinki, Finland \\ Corresponding author: Jouko Rikkinen (jouko.rikkinen@helsinki.fi)
}

Academic editor: T. Lumbsch | Received 17 August 2012 | Accepted 21 November 2012 | Published 23 April 2013

Citation: Rikkinen J (2013) Molecular studies on cyanobacterial diversity in lichen symbioses. In: Boonpragob K, Crittenden P, Lumbsch HT (Eds) Lichens: from genome to ecosystems in a changing world. MycoKeys 6: 3-32. doi: $10.3897 /$ mycokeys.6.3869

\begin{abstract}
Symbioses between cyanobacteria and lichen-forming fungi occur worldwide in a wide range of terrestrial environments, ranging from tropical rainforests to hot and cold deserts. The evolutionary success of these symbioses is evident from the wide range of fungal groups that have established associations with cyanobacteria. The diversity of symbiotic cyanobacteria is also high, and it is obvious that symbioses between different cyanobacteria and different lichen-forming fungi have evolved on multiple occasions. From the late 1990s cyanobacterial lichens have been the subject of a steadily increasing number of molecular investigations. This chronological review examines how these studies have contributed to present knowledge and highlights some conceptual developments that have been instrumental in the process.
\end{abstract}

\section{Key words}

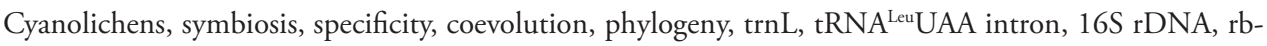
cLX, Nostoc, Collema, Nephroma, Pannaria, Peltigera, Pseudocyphellaria

\section{Introduction}

Lichens are symbiotic associations between a fungus and a photosynthetic partner that may be a eukaryotic alga or cyanobacterium. While a clear majority of lichen-forming fungi, mainly Ascomycota, associate with green algae, over 1500 species of lichenforming fungi have cyanobacteria as primary or accessory photosynthetic partners and are therefore collectively referred to as "cyanolichens". Cyanobacterial symbioses have evolved repeatedly in different lineages of lichen-forming Fungi, and often con-

Copyright Jouko Rikkinen. This is an open access article distributed under the terms of the Creative Commons Attribution License 3.0 (CC-BY), which permits unrestricted use, distribution, and reproduction in any medium, provided the original author and source are credited. 
vergent evolution has led to superficially similar thallus structures in distantly related cyanolichens (Rikkinen 2002).

Within lichen thalli the symbiotic cyanobacteria contribute to the host fitness by provisioning sugar and/or fixed atmospheric nitrogen. In return, the fungal host provides the cyanobacteria with a relatively stable environment, host-derived water and carbon dioxide, and a special niche that is relatively well protected from environmental extremes and predation. In many cases the cyanobacterial symbionts are vertically transmitted within specialized asexual propagules and maintained through host generations, insuring a close and long-term symbiosis. Most lichen symbioses are thought to be obligate as the fungal hosts cannot survive without their photosynthetic partners and the cyanobacterial symbionts do not seem to commonly establish aposymbiotic populations outside lichen thalli.

Lichen symbioses are often perceived as pair wise interactions between a single fungal host and a single photosynthetic symbiont. However, many lichen-forming fungi are in fact associated with two or more species of photobionts. In most bipartite cyanolichens the cyanobacterial symbiont forms a more or less continuous layer immediately below the upper cortex of the thallus (Figs 1A-B). Tripartite cyanolichens, on the other hand, house both green algal and cyanobacterial symbionts. In these lichens the cyanobacteria, which usually represent a minor proportion of total photobiont biomass, are restricted to special structures called cephalodia (Figs 1C-D). Hundreds of lichen species are known to have external or internal cephalodia. In addition, some green algal lichens commonly establish ephemeral associations with free-living cyanobacteria, most probably in order to access a supply of fixed nitrogen.

The fungal hosts of certain tripartite lichens (some species of Lobaria, Nephroma, Peltigera, Pseudocyphellaria, and Sticta) can occasionally produce different thallus morphologies in symbiosis with compatible green algae and cyanobacteria. Chimeroid lichens with green algae and cyanobacteria as primary photobionts in different parts of the same thallus are called photosymbiodemes. The contrasting morphotypes may either combine into a compound thallus or, in some cases, live separate lives.

Lichen-symbiotic cyanobacteria can deliver photosynthate and/or fixed nitrogen to their fungal partners. The relative importance of these activities is known to vary between bi- and tripartite lichens. The cyanobionts of bipartite lichens often show lower heterocyst frequencies and lower rates of nitrogen fixation than those of tripartite species. In tripartite cyanolichens, the cyanobionts usually show relatively high rates of nitrogen fixation, while the green algal photobiont typically delivers most of the photosynthate.

Nostoc is by far the most common genus of cyanobacteria in lichens, especially in the temperate and cool regions of the world. The lichen symbiontic Nostoc genotypes are closely related to plant symbiotic and free-living forms of the same genus (Fig. 2). All Nostoc species are filamentous and have complex life cycles. Their non-branching filaments consist of cylindrical or spherical vegetative cells with intercalary heterocysts (large nitrogen-fixing cells) developing in mature trichomes (Figs 2D-E). The filaments are usually covered in mucilage and many free-living Nostoc genotypes can form large gelatinous colonies (Figs 2A-B). 


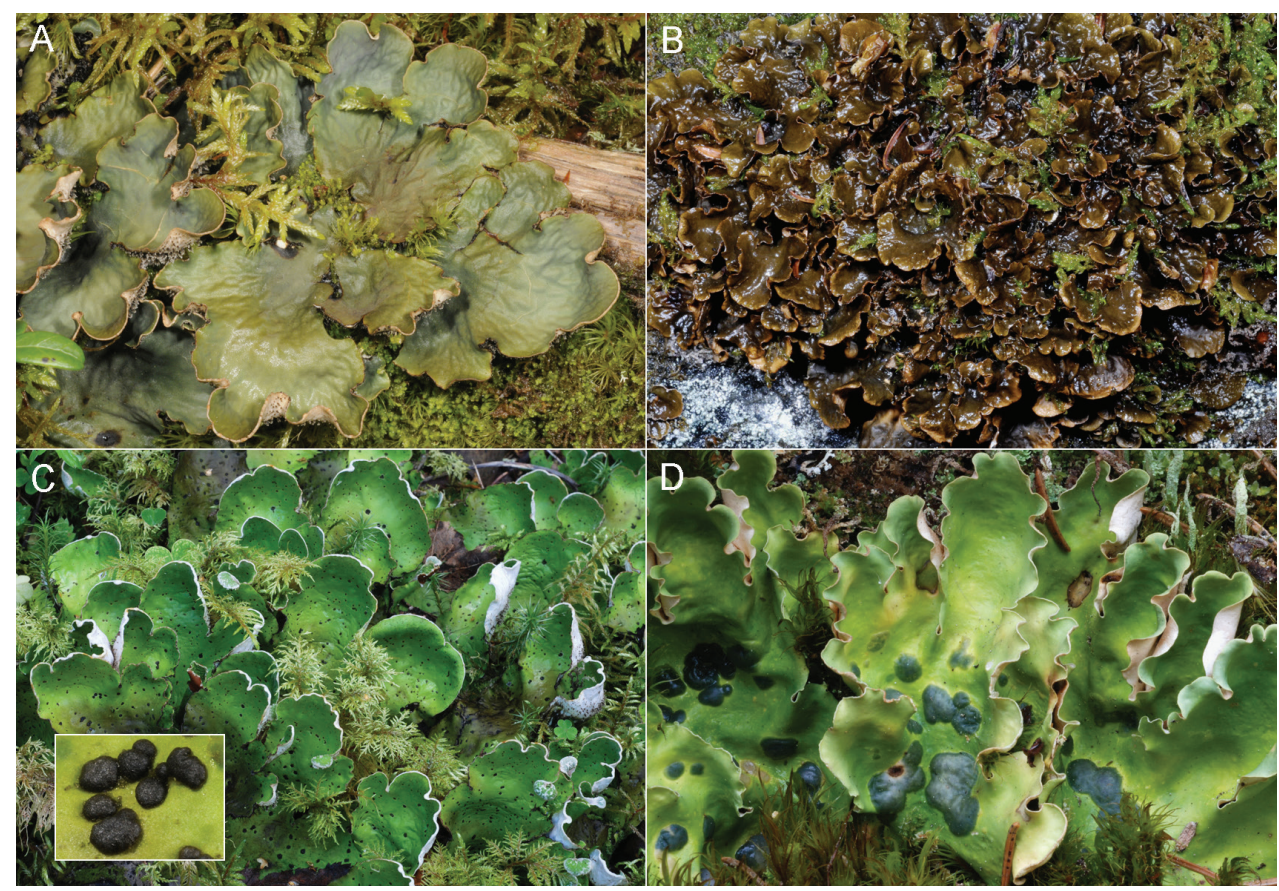

Figure I. Bipartite and tripartite cyanolichens. A In the bipartite cyanolichen Peltigera scabrosa the cyanobacterial symbiont (Nostoc) forms a continuous layer just below the upper cortex of the lichen thallus B Nephroma bellum is another example of bipartite cyanolichens $\mathbf{C}$ In the tripartite cyanolichen Peltigera aphthosa the Nostoc symbiont is restricted to wart-like cephalodia (shown magnified) on the upper surface of the thallus, while the green algal symbiont (Coccomyxa) forms the photobiont layer D Nephroma arcticum is another example of tripartite cyanolichens. The large cephalodia of this species are internal, but clearly visible through the upper cortex of the hydrated thallus.

At present, symbiotic Nostoc genotypes and other lichen symbiotic cyanobacteria cannot be reliably identified to species. This relates to a general confusion in the species level taxonomy of cyanobacteria. From early in the 19th century to the mid 20th century numerous genera and species of blue-green algae were described on the basis of morphological characteristics and life-history traits (e.g. Geitler 1932). While DNA data have since confirmed that cyanobacteria represent a lineage among the Eubacteria, cyanobacterial taxa can still be described following two sets of rules, i.e., those of the Botanical and the Bacteriological Code of Nomenclature, respectively (e.g. Oren 2004). While the taxonomic criteria of many botanical cyanobacterial groups were established more than a century ago, adequate type material is available for relatively few species. Most early species descriptions were based on insufficient observations, and many taxa were defined using unstable features. Furthermore, many morphological characteristics of free-living cyanobacteria are not apparent within lichen thalli, as the morphology and development of the organisms tend to be modified in symbiosis.

The Nostoc symbionts of many cyanolichens, including both bi- and tripartite species of Peltigera, have usually been called Nostoc punctiforme, but also cyanobacterial 


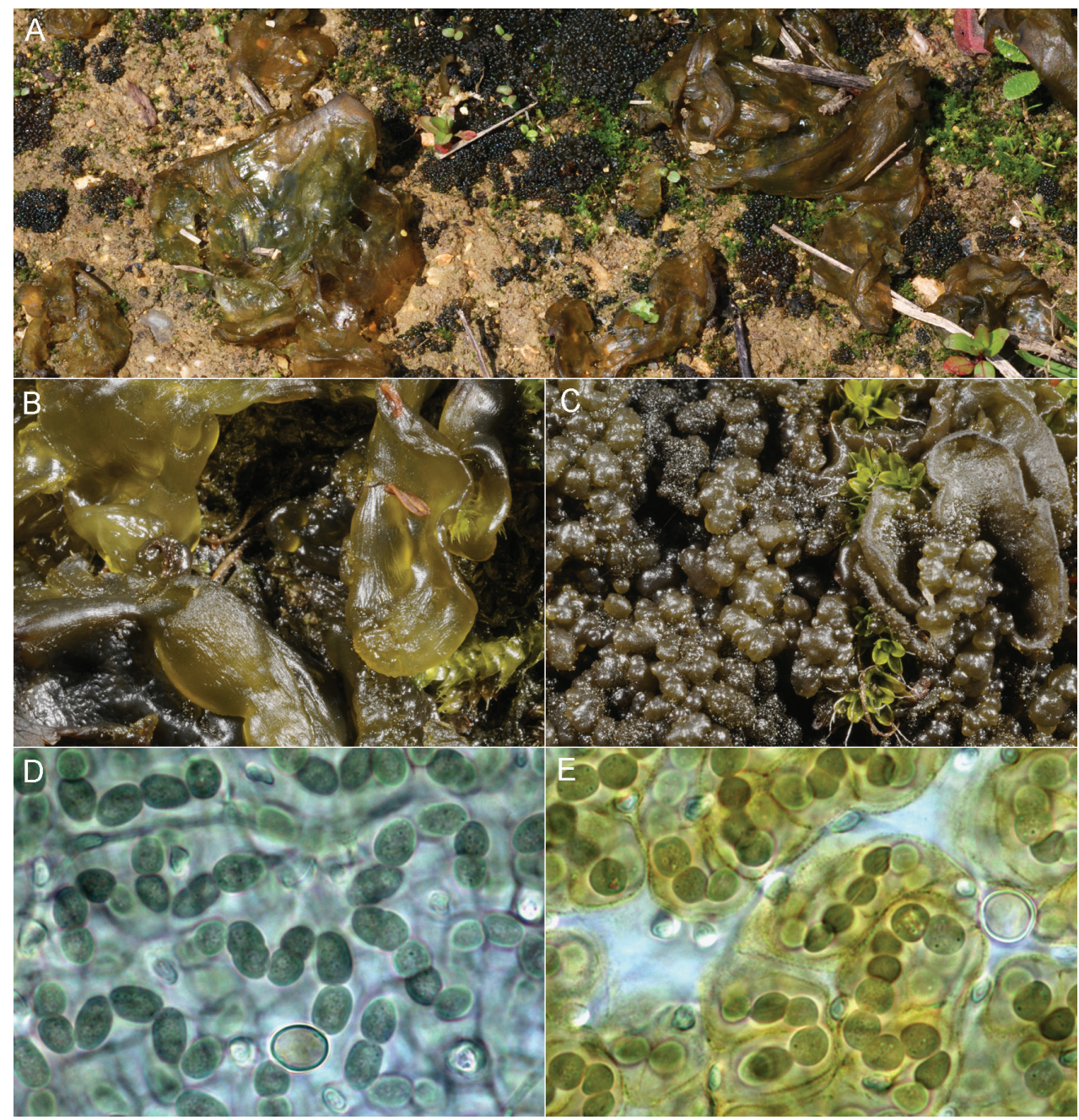

Figure 2. Free-living and lichen-symbiotic Nostoc strains. A Free-living Nostoc colonies and gelatinous cyanolichens (Collema sp.) growing on mineral soil in northern Spain B Free-living Nostoc colony on limestone in northern Italy C Lichenized Collema thallus (containing Nostoc symbionts) on limestone in northern Italy D-F Morphological variation of Nostoc symbionts inside two Leptogium thalli in southwestern Kenya. The large clear cells are nitrogen-fixing heterocysts, the smaller translucent structures are fungal hyphae in optical cross-section.

strains resembling $N$. muscorum, $N$. sphaericum and $N$. linckia have been cultured from some Peltigera species (e.g. Forssel 1883, Bergman and Hällbom 1982, TschermakWoess 1988). Degelius (1954) pointed out that $N$. punctiforme may not represent any one taxon, but rather include developmental stages (e.g. Mollenhauer 1988) of several different Nostoc species. Feige (1978) found both intra- and infraspecific differences in the lipid patterns of cyanobacterial heterocysts from Peltigera species indicating that several different cyanobacterial species would be involved in these lichens. Further- 
more, tripartite Peltigera and Nephroma species have sometimes been found to possess several different cyanobacterial morphotypes within single thalli and occasionally even in the same cephalodium (Jordan and Rickson 1971). The cephalodia of some Stereocaulon species may even contain cyanobacteria of several different genera (TschermakWoess 1988).

As a whole, in symbiosis the few structural features of cyanobacteria tend to be strongly modified, making the accurate identification of morphospecies impossible. Thus, molecular techniques offer the only practical methods for studying the genetic diversity of these organisms, and for making comparisons between lichen symbiotic and other symbiotic or free-living cyanobacteria. During the past fifteen years the cyanobacterial symbionts of lichens have been the subject of many molecular investigations which have greatly increased our understanding of symbiont diversity in these interesting systems. The following chronological review describes how such studies have gradually built up our present knowledge and examines some conceptual developments that have been important in the process.

\section{From single thalli to global distribution patterns}

The first DNA-based studies on lichen-symbiotic cyanobacteria were those of Kardish et al. (1989, 1990) who by using Southern hybridizations got different patterns from laboratory cultures and fresh Nostoc isolates from the bipartite cyanolichen Nephroma laevigatum. Leizerovich et al. (1990) used the same method to compare Nostoc cultures from several bipartite cyanolichen species, two thalloid bryophytes, Cycas, Gunnera, and a free-living specimen. The hybridization patterns were diverse and did not appear to correlate with the phylogenic position of the host organisms. Several years later, using cyanobacterial 16S rDNA sequences, Miao et al. (1997) detected different Nostoc genotypes in two Peltigera membranacea thalli from western North America. However, only one Nostoc genotype could be cultured from the lichen specimens. The two thalli analyzed represented different color forms of the bipartite cyanolichen species.

These early studies indicated that while individual lichen thalli seemed to contain a rather limited variety of cyanobacteria, isolating and culturing the correct symbiont could be difficult. Similar experiences had previously been gained from studies on plant-cyanobacterial symbioses, especially those concerning the water fern Azolla. The findings emphasized the general need to first identify symbiotic cyanobacteria directly from lichen thalli, before trusting the identification of symbionts in culture.

Paulsrud and Lindblad (1998) pioneered the use of cyanobacterial trnL sequences in lichen studies by identifying Nostoc genotypes from several specimens of the tripartite cyanolichen species Nephroma arcticum (Fig. 1D) and Peltigera aphthosa (Fig. 1C), and the bipartite species Peltigera canina and P. membranacea from boreal forests in Sweden. The results demonstrated that the symbionts of the studied lichens did not consist of a community of different strains but, rather, of one Nostoc genotype in each lichen thallus. Although several different Nostoc trnL genotypes were identified in the 
study, even from lichens growing close to each other, no variation was observed within a sample or within a single lichen thallus. Similar conclusions have since been reached concerning all bipartite cyanolichens analyzed in subsequent studies. The authors discussed possible reasons for the apparent lack of variation within one thallus, and particularly that in tripartite lichens species, where the symbiont population is confined to small cephalodia separated by wide cyanobacterium-free areas of only fungus and green alga, and concluded that each lichen species was probably restricted in their choice of cyanobiont to a relatively small number of Nostoc strains. In any case, the sequence patterns of Nostoc trnL genotypes in the studied lichens were clearly more restricted by the species identities of fungal hosts than by the spatial segregation of lichen thalli.

Paulsrud et al. (1998) expanded the earlier sampling by identifying Nostoc symbionts from additional lichen specimens from central Finland. The study revealed that the same Nostoc trnL genotypes that had been identified from Sweden were also present in Finnish specimens of Peltigera aphthosa, Peltigera canina, and Nephroma arcticum. The cephalodia of the two tripartite lichen species analyzed always contained different Nostoc trnL genotypes, with two different genotypes occurring in different thalli of both species in both countries. They also identified Nostoc symbionts in the cephalodia and bipartite thallus sections of a Peltigera aphthosa photosymbiodeme collected from Finland and found that the same Nostoc genotype was present in both parts of the chimeroid lichen thallus. This indicated that a single Nostoc genotype was able to participate in the two structurally different symbioses of bipartite and tripartite lichens, respectively. Two Nostoc trnL intron genotypes were identified from different Peltigera neopolydactyla specimens from Finland. One of these was very similar to those found from P. canina and P. membranacea, and since from numerous other bipartite Peltigera species (Fig. 1A), while the second genotype was identical to that identified from several specimens of $P$. aphthosa from both Finland and Sweden. This confirmed that some cephalodial Nostoc genotypes also occurred in bipartite cyanolichens. Finally, a new trnL intron type, characterized by a peculiar inserted sequence in the P6b region, was found from an epiphytic Nephroma resupinatum thallus from Finland.

Paulsrud et al. (2000) continued to widen the sampling by identifying Nostoc symbionts from new cyanolichen specimens from different localities in Oregon and Washington in western North America. A single Nostoc trnL genotype was again found in each lichen thallus in all except one lichen species. The exception was Peltigera venosa (Fig. 3C), in which different Nostoc genotypes were identified from different cephalodia in several thalli. However, in a photosymbiodeme of this species, the same Nostoc genotype was found both in the cephalodia and a free-living cyanosymbiodeme collected from one locality. In Peltigera britannica, two different Nostoc genotypes were identified from cephalodia of different thalli, and the more common genotype was also found in one cephalodium of $P$. venosa. In the bipartite cyanolichen species, two different Nostoc genotypes were found in different thalli of the local Peltigera neopolydactyla. Both of these were different than those previously identified from Finnish specimens of the same species complex. However, one of the new Nostoc genotypes, that was also found from two Peltigera membranacea specimens from Oregon, was sequence 


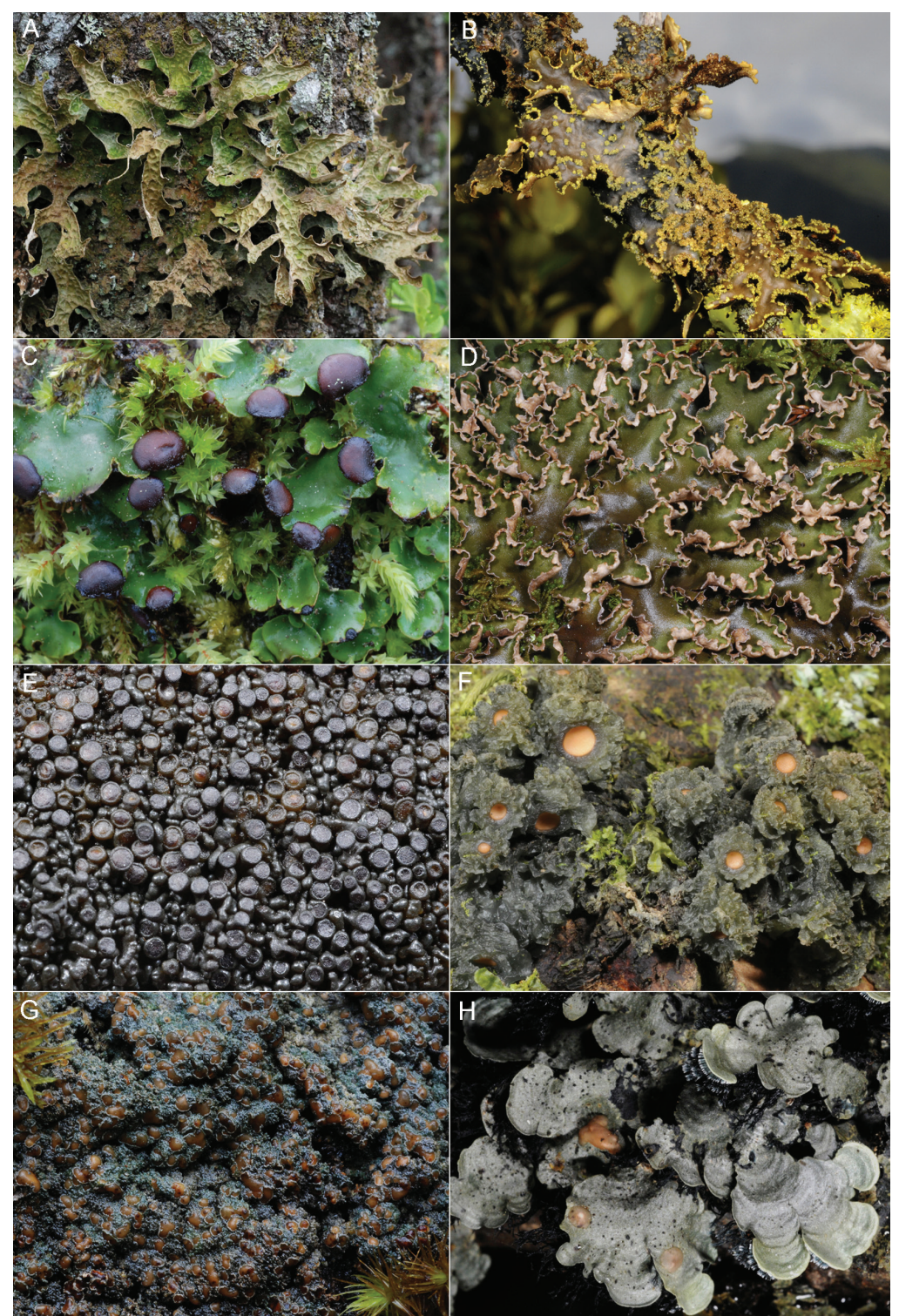

Figure 3. Examples of cyanolichens examined in molecular studies of cyanobacterial diversity. A Cephalodial symbionts of the tripartite cyanolichen Lobaria pulmonaria remain poorly known (e.g. Rikkinen et al. 2002, Myllys et al. 2007) B Nostoc symbionts of Pseudocyphellaria species have been analyzed in several studies (e.g. Summefield et al. 2002, 2006, Rikkinen et al. 2002, Stenroos et al. 2006) C Peltigera venosa may have different Nostoc genotypes in different cephalodia (Paulsrud et al. 2000) D Nostoc symbionts of bipartite Peltigera species have been identified in many studies (e.g. Paulsrud and Lindblad 1998, O’Brien et al. 2005, Kaasalainen et al. 2012) E Otalora et al. (2010) analyzed genetic diversity of Nostoc in Collema and related cyanolichens F Many tropical Leptogium specimens were screened by Kaasalainen et al. (2012) G A Nostoc strain isolated from Pannaria pezizoides produces potent hepatotoxins in culture (Oksanen et al. 2004, Kaasalainen et al. 2009) $\mathbf{H}$ The cyanobacterial symbionts of Coccocarpia species are only distantly related to Nostoc (Lücking et al. 2009). 
identical to that previously identified from $P$. membranacea in Sweden. Also the Nostoc genotype now found from Nephroma resupinatum in Oregon was quite similar to that previously found from the same lichen species in Finland. However, it did not have the peculiar insertion in the $\mathrm{P} 6 \mathrm{~b}$ region of the trnL intron.

The new findings indicated that some patterns of symbiont specificity could hold true over vast geographical distances. Many of the cyanolichen specimens analyzed came from mixed collections of different cyanolichen species growing in close physical contact, adding evidence that it was the lichen species, not locality, that was important in determining cyanobiont identity. Comparable diversity of Nostoc genotypes to that observed in P. venosa had not been encountered previously, and this was also the first time when several Nostoc genotypes were found from different cephalodia of a single thallus of a tripartite cyanolichen. The authors discussed reasons for the apparent promiscuity in symbiont choice and proposed that it might be explained by the unusual development and ecology of $P$. venosa. Its special features include cephalodia on the lower surface of the thallus, the capability of forming different thallus types or developmental stages under different environmental conditions and, possibly, an additional ability to exhibit different degrees of lichenization with different Nostoc strains. Finally, the trnL sequence from Nephroma resupinatum focused attention to the apparent difference in Nostoc genotypes of bipartite Nephroma and Peltigera species, and to variation in the occurrence of peculiar indels in the P6b region of trnL sequences. Since then these have been reoccurring themes in several studies.

Paulsrud et al. (2001) took a closer look at cyanobacterial specificity in Peltigera aphthosa (Fig. 1C) by attempting to experimentally introduce foreign cyanobacterial genotypes into established lichen thalli in the field. All Nostoc strains used in the experiment were identifiable on the basis of trnL sequences. The experiment relied on the fact that cephalodia on the upper surface of $P$. aphthosa could be experimentally removed without killing the lichen: under favorable conditions new cephalodia would develop within a few weeks. Thalli of $P$. aphthosa were manipulated by removing all cephalodia and then inoculating the thalli with cultured cyanobacteria. Five different lichen-symbiotic Nostoc strains were used in the inoculations, originating from Peltigera aphthosa (both of the two Nostoc genotypes previously found from different P. aphthosa thalli in Sweden and Finland), P. canina, P. membranacea, and Nephroma resupinatum. In addition to the lichen-symbiotic strains, also two laboratory strains of Nostoc were used. After inoculation and subsequent growth, 80 new cephalodia and seven epiphytic Nostoc colonies were collected and analyzed. All cephalodia were found to contain the same Nostoc genotype, this being identical to that identified from the cephalodia excised from the lichen thalli at the beginning of the experiment. Thus, the original Nostoc symbiont turned up in every new cephalodium despite massive inoculations of six other Nostoc strains. Interestingly, two inoculated Nostoc strains, those isolated from $P$. canina and $P$. membranacea, could live and reproduce on the surface of manipulated lichens. Thus, while never finding their way into new cephalodia, by the end of the experiment they had formed thriving epiphytic colonies on the upper surfaces of some $P$. aphthosa thalli. 
Summerfield et al. (2002) presented the first molecular study of cyanobacterial diversity in lichens of the southern hemisphere. They identified Nostoc trnL genotypes from specimens of four species of Pseudocyphellaria (Fig. 3B) collected from different sites in the South Island, New Zealand. Nostoc strains were isolated from some thalli and the identity of the isolates was confirmed by using trnL and partial $16 \mathrm{~S}$ rDNA sequences. Also the identity of the fungal hosts was determined on the basis of fungal ITS sequences. The results showed that $P$. crocata and $P$. neglecta always housed different Nostoc symbionts. Furthermore, one Nostoc strain was again found to associate with more than one mycobiont, in this case $P$. crocata and $P$. maculata. Interestingly, the Nostoc genotype of $P$. crocata from New Zealand was nearly sequence identical to that previously reported from Nephroma resupinatum in central Finland. The authors concluded that the cyanobiont association of the two bipartite Pseudocyphellaria species was highly specific, and that a similar specificity had thus now been demonstrated in lichens belonging to three families of the suborder Peltigerineae from both the northern and southern hemispheres.

Costa et al. (2002) used the trnL method to analyze cyanobacterial diversity in two thalloid bryophytes, the hornwort Anthoceros fusiformis from western North America and the liverwort Blasia pusilla from central Finland (Figs 6A-B). The results showed that several different Nostoc genotypes were involved in both bryophyte symbioses and the level cyanobacterial diversity within individual bryophyte thalli was quite variable. Some Nostoc genotypes were detected from Blasia thalli collected from different sites and in different years, indicating a moderate level of spatial and temporal continuity in this symbiosis. One Nostoc genotype that was identified several times from Blasia thalli was identical to one of the symbionts that had previously been identified from the bipartite cyanolichen Peltigera neopolydactyla in central Finland. Also the sequences of several other bryophyte-associated Nostoc genotypes were very similar to those of lichen symbionts indicating that both symbionts belonged to the same linage. One new Nostoc genotype was identified from a Peltigera didactyla thallus growing amongst Blasia thalli. It differed slightly from Nostoc genotypes in neighboring bryophytes, but was nearly identical to a Nostoc symbiont that had been previously found from a Peltigera britannica cephalodium in western North America.

Costa et al. (2002) analyzed the variation in cyanobacterial trnL intron sequences in more detail and described how it was not random but strongly restricted by the secondary and tertiary structure of the transcribed intron. All Nostoc sequences analyzed shared high sequence similarity, but major differences were commonly seen in the P6b region, corresponding to one stem-loop in the transcribed intron. As already described in Paulsrud and Lindblad (1998), the Nostoc trnL sequences could be grouped into two classes, corresponding to distinct base pairing heptanucleotide repeats that built up the P6b region. Length variation in the sequences was mainly caused by different numbers of repeats, but some Nostoc strains also contained additional sequences in this region not following the heptanucleotide repeat motif. Several sequences showing similarity with these additional sequences were identified in the recently published Nostoc punctiforme genome. Furthermore, the regions flanking these sequences contained similar 
heptanucleotide repeats as those flanking the corresponding sequences in the intron. It was proposed that slipped strand mispairing during replication and homologous recombination among different loci in the genome would have been important processes causing the present variation between intron types.

Oksanen et al. (2002) studied cyanobacterial diversity in a series of small, interconnected rock-pools on a limestone pavement in western Ireland. The purpose was to determine whether or not the cyanobacterial symbionts of Collema multipartitum and neighboring free-living Nostoc colonies belong to the same genotype (Figs 2B-C). One Nostoc trnL genotype was identified from three different Collema specimens, while another Collema specimen contained a second genotype. A third Nostoc genotype was isolated into culture from an additional lichen thallus. The presence of fungal DNA was confirmed in all these specimens. Five different Nostoc genotypes were identified from free-living colonies and no fungal DNA was obtained from any of them. The consistent difference between the Nostoc genotypes in Collema thalli and free-living colonies indicated that a different group of Nostoc was associated with each biological system in the restricted rock-pool environment. While the Nostoc genotypes that formed large colonies in deep depressions appeared to be free-living, some of them might still have been potentially lichen symbiotic. This was indicated by the fact that one free-living Nostoc genotype was sequence identical with another that had previously been identified from a thallus of Peltigera neopolydactyla in Oregon.

Rikkinen et al. (2002) compared cyanobacterial diversity in cyanolichen specimens collected from boreal forests of northern Europe and temperate forests of western North America and central China (Figs 5B-C). Epiphytic lichen communities in two boreal forests in central Finland were studied in some detail, and there some cyanobacteria were also isolated from epiphytic substrates. Cyanobacterial 16S rDNA sequences were used to resolve phylogenetic relationships, and trnL sequences were used to identify Nostoc genotypes. Most epiphytic cyanolichens in central Finland were found to associate with a small group of closely related Nostoc trnL genotypes. One particular genotype was identified from all six research sites, and it was shared extensively by three different Nephroma species and Parmeliella triptophylla. Several epiphytic cyanolichen specimens from western North American and central China contained similar Nostoc trnL genotypes, and the phylogenetic relationship between the genotypes was confirmed by the $16 \mathrm{~S}$ rDNA phylogeny. A different set of Nostoc trnL genotypes was found from Finnish Peltigera specimens and from Nostoc isolates cultured from substrate samples. A congruent pattern was again seen in lichen specimens collected from Asia and North America, and the existence of two distinctive groups of Nostoc trnL genotypes was also confirmed by $16 \mathrm{~S}$ rDNA data.

The new findings suggested that some cyanolichens could express their Nostoc specificity on a community scale (Fig. 4). Thus, in central Finland the predominately epiphytic, bipartite Nephroma species and P. triptophylla seemed to rely on a common pool of cyanobacterial symbionts and potentially form a horizontally linked system, the Nephroma guild. Conversely, some more predominately terricolous cyanolichen species, like Peltigera praetextata housed a completely different group of related Nostoc 


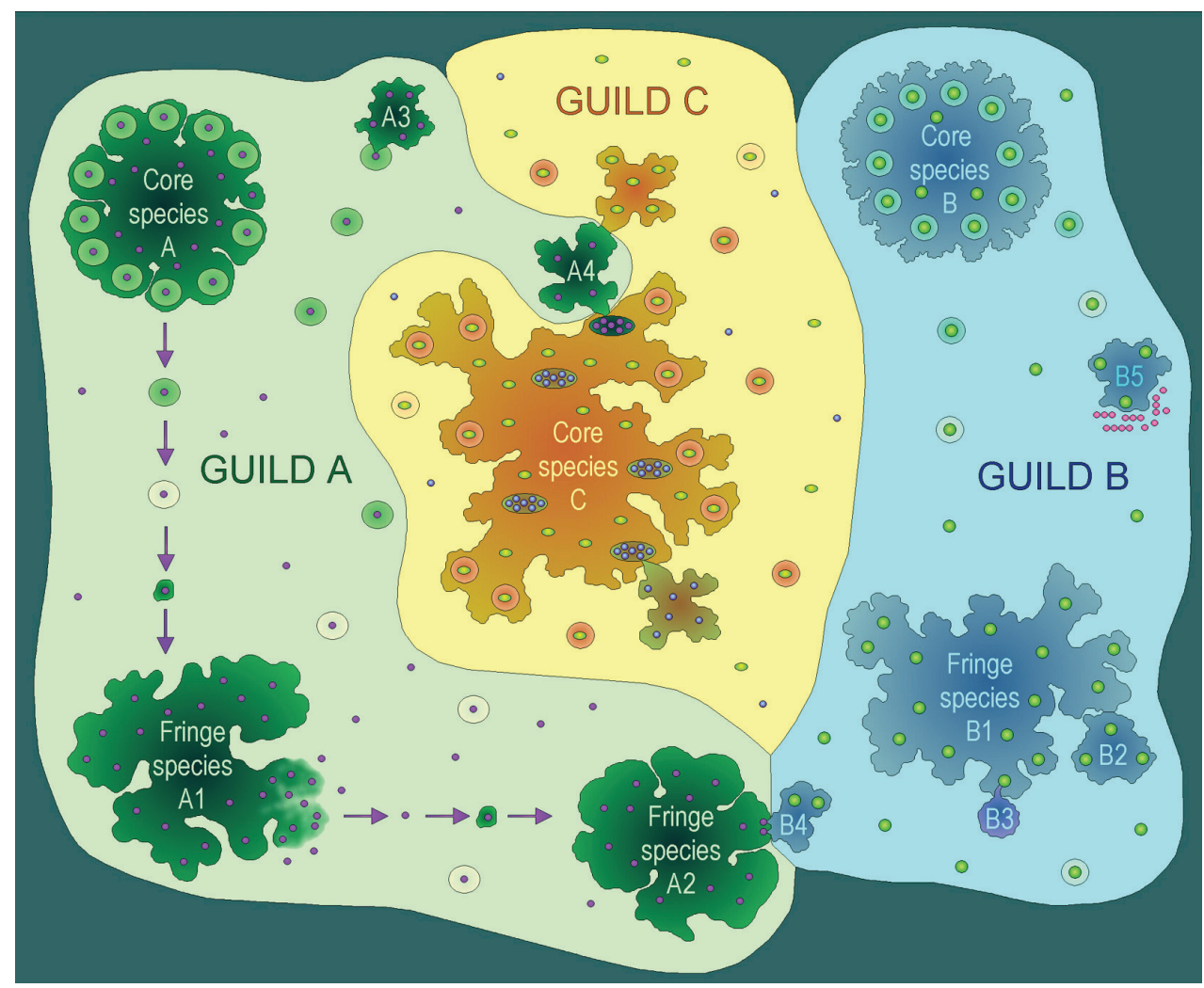

Figure 4. Photobiont-mediated guilds in lichens (modified from Rikkinen 2003). The lichen-forming fungi belong to three different guilds, one centring around cyanobacterial symbionts $(\mathbf{A})$, the second around green algal symbionts $(\mathbf{B})$, and the third around another genus of green algal symbionts $(\mathbf{C})$. The lichen in the middle of the picture houses both green algae and cyanobacteria (in cephalodia), meaning that its fungal symbiont can operate in two different guilds $(\mathbf{C}$ and $\mathbf{A})$. As the symbiotic propagules of this lichen only contain the fungus and green algal photobiont, the fungus is a core species in guild $\mathbf{C}$ and a fringe species in guild $\mathbf{A}$. Under certain conditions this fungus may give rise to cyanobacterial morphotypes (A4) and/or green algal thallus lobes. The core species of the lichen guilds produce innumerable symbiotic propagules, most of which will never develop into mature thalli of that lichen species. Germinating spores of fringe species (A1-A4, B1-B5) may commonly acquire their photobionts from small free-living populations that originate from disintegrating symbiotic propagules of the core species. At the latest when the thallus of a fringe species dies and disintegrates (A1), some of the photobionts are released back to the local environment for the common benefit of all fungi of the same guild. However, without the ability to produce symbiotic propagules, the fringe species cannot effectively disperse appropriate photobionts into new habitats. Some fringe species are aggressive enough to steal photobionts from juvenile stages or weakened thalli of other lichen species (A3), or live as lichenicolous lichens (B2) on other lichens of the same guild. The juvenile stages of some green algal lichens establish loose cyanotrophic associations with free-living cyanobacteria (B5) and/or cyanolichens (B4). Some lichenicolous fungi (B3) have evolved from lichen-forming ancestors and in many cases also their host ranges still appreciate guild boundaries. 


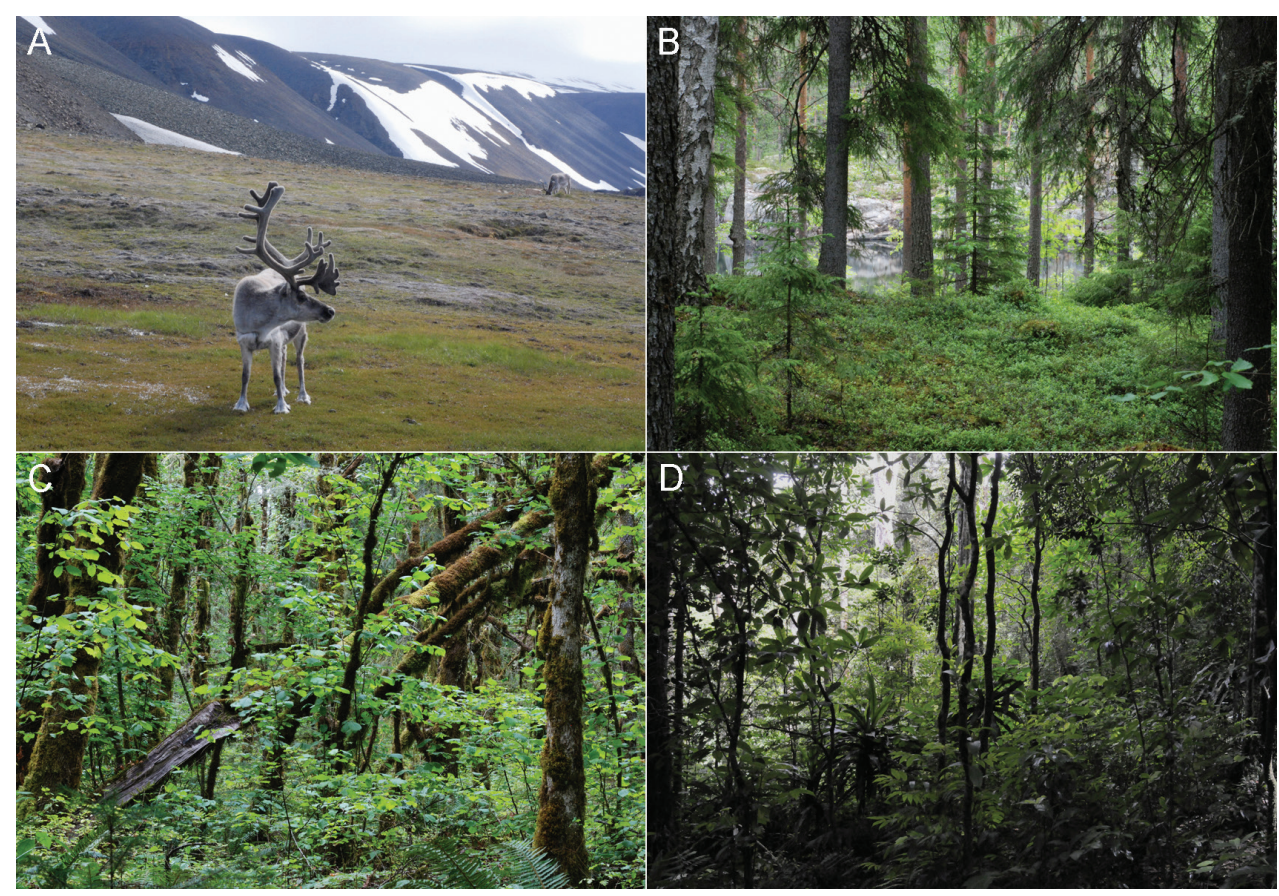

Figure 5. Environments sampled in molecular studies of cyanobacterial diversity. A Arctic tundra on Svalbard; so far only two studies have included cyanolichen specimens from polar environments (Wirth et al. 2003, Kaasalainen et al. 2012) B Boreal forest in central Finland; cyanolichens from boreal forests have been examined in several studies (e.g. Paulsrud and Lindblad 1998, Myllys et al. 2007, Fedrowitz et al. 2011) C Temperate forest in western North America; also cyanolichens from temperate forests have been analyzed in several studies (e.g. Rikkinen et al. 2002, Summerfield et al. 2002, Fedrowitz et al. 2011) D Tropical montane forest in East Africa; so far only two studies have included cyanolichen specimens from tropical ecosystems (Lücking et al. 2009, Kaasalainen et al. 2012).

strains, thus forming the Peltigera guild. It was also proposed that the dispersal ecology of such lichen guilds could involve "core species" which produce large amounts of symbiotic propagules. "Fringe species" would in turn only propagate via fungal spores and thus partly depend on core species for the dispersal of appropriate symbionts. In any case, the high sequence similarity between Nostoc symbionts of phylogenetically distant but ecologically similar cyanolichens in different parts of the world suggested that photobiont-mediated guilds may have played an important role in the evolution of the presently observed diversity among lichen symbiotic organisms.

Lohtander et al. $(2002,2003)$ expanded studies on the diversity of symbiotic Nostoc in the cyanolichen genus Nephroma (Figs 1B, 1D). First, phylogenetic analyses confirmed that all European Nephroma species, as traditionally circumscribed, could be identified on the basis of fungal ITS sequences. The results showed that the tripartite species did not form a monophyletic group within the genus. Concurrently, transitions from a bipartite symbiosis to a tripartite symbiosis, or vice versa, must have occurred repeatedly during the evolution of Nephroma. Next, the genetic diversity of 
green algal and cyanobacterial symbionts in Nephroma was examined. Minimal variation was found in green algal ITS genotypes of the tripartite species $N$. arcticum and $N$. expallidum. Almost identical sequences were also obtained from thalli of two tripartite Peltigera species ( $P$. aphthosa and P. leucophlebia). In contrast, the diversity of symbiotic Nostoc in Nephroma was found to be high. In accordance with earlier results, a phylogenetic analysis of partial $16 \mathrm{~S}$ rDNA sequences demonstrated that all symbiotic Nostoc formed a monophyletic group with two main subgroups. The first of these corresponded to the previously identified Nephroma guild cyanobionts, and this included the Nostoc symbionts of all bipartite Nephroma species. The second group included the cyanobionts of many terricolous lichens, including several Peltigera species, but also the Nostoc symbionts of the two tripartite Nephroma species analyzed. This was interesting as it implied that within Nephroma, evolutionary transitions between bi- and tripartite symbioses could not have been achieved simply via the acquisition or loss of the green algal photobiont; they must have also required a concurrent switch of cyanobacterial symbionts. This may account for the apparently poor fitness of $N$. arcticum photosymbiodemes, for example. While these bipartite cyanomorphs have lost their green algal symbionts, they may still continue to house the "wrong" cyanobacterial genotype. As a whole, the new findings confirmed that lichen symbiotic Nostoc genotypes do not always group according to the species identities of their fungal hosts. For example, while $N$. resupinatum formed a sister group to all the other Nephroma species analyzed, the Nostoc symbionts of this species were often sequence-identical to those identified from other bipartite Nephroma species.

Linke et al. (2003) identified trnL genotypes of cyanobacteria from three Peltigera species and two Nostoc isolates obtained from named culture collections. The Peltigera species examined included a specimen of the aquatic species $P$. hydrothyria from western North America. The Nostoc genotypes obtained were closely related to those previously identified from other cyanolichens and from environmental isolates, demonstrating the power of trnL sequences as a tool of identifying lichen symbiotic Nostoc strains. The close relationship between lichen symbionts and named laboratory strains indicated that cyanobacterial genotypes belonging to several different botanical Nostoc species were present in different cyanolichens.

The geographical scope of earlier studies was expanded considerably by Wirtz et al. (2003) who identified cyanobacterial trnL genotypes from five cyanolichen species and free-living Nostoc colonies collected from several localities in two ice-free inland habitats on Livingston Island, maritime Antarctica. Lichen specimens from polar environments had not been analyzed in previous studies (Fig. 5A). Two of the lichens (Leptogium puberulum and Massalongia carnosa) were bipartite lichens, while the other three were tripartite species (Placopsis contortuplicata, Placopsis parellina and Psoroma cinnamomeum). In total, 64 specimens were examined, including four specimens of $P$. parellina collected in Argentina. The results revealed that Antarctic Nostoc genotypes formed two major groups, corresponding to the two different heptanucleotide repeat classes. The Nostoc genotypes from specific lichen species did not group according to their fungal hosts but several genotypes were widely intermixed between different 
hosts. Three different genotypes were identified from the free-living Nostoc colonies and two of these were also found from some lichen thalli. The cyanobionts identified form Argentine populations of $P$. parellina were similar to each other but differed clearly from the Antarctic cyanobionts. The authors proposed that the low photobiont specificity observed might have been due to a limited number of lichen symbiotic Nostoc strains available, as a result of the extreme Antarctic environmental conditions. Accordingly, lichen mycobionts could survive only if they were relatively non-specific in their choice of cyanobacterial symbionts. Also a decrease in the number of cyanolichen species with increasing latitude might, in part, reflect the effects of a strong selection pressure against highly specific lichen mycobionts in extreme environments.

Oksanen, Lohtander et al. (2004) studied the evolution of trnL introns in heterocystous cyanobacteria and compared the utility of trnL sequences as a phylogenetic marker to that of $16 S$ rRNA gene, the conventional marker in Eubacteria. Previous findings had supported the presumption that studies based on trnL sequences and $16 \mathrm{~S}$ rDNA sequences of lichen symbiotic Nostoc genotypes produced qualitatively similar results - the resolution of the two markers was somewhat different, but the diversity patterns revealed were broadly congruent. However, as the evolution of trnL introns was known to be complex (Kuhsel et al. 1990, Xu et al. 1990, Paquin et al. 1997, Besendahl et al. 2000) and controversial (Rudi and Jakobsen 1997, 1999, Rudi et al. 2002), and because the evolution of the P6b region was particularly puzzling, this type of analysis was of considerable interest. The results confirmed that nucleotide differences in the P6b region of Nostoc trnL intron sequences were tricky to use in phylogenetic analyses. In the more conserved parts of these sequences, the small number of informative characters restricted phylogenetic group formation, this being related to short sequence length and the stable secondary and tertiary structure required by the self-splicing property of the group I intron. Hence, the conserved parts of trnL sequences alone did not provide enough sequence variation for hierarchical analyses. Nevertheless, phylogenetic analyses of the conserved parts of trnL sequences generally resulted in results similar to those based on the $16 \mathrm{~S}$ rRNA gene, and thus provided additional support for $16 \mathrm{~S}$ rDNA phylogenies. It was also noted that one should not explicitly trust $16 \mathrm{~S}$ rRNA gene phylogenies alone without knowledge of possible variation among different gene copies.

Rikkinen (2004) reviewed all cyanobacterial trnL sequences that had become available by that time. The data set of 606 sequences was analyzed with multivariate methods, as a step towards putting all identified Nostoc trnL genotypes into meaningful contexts. The data set included many Nostoc genotypes from lichens and bryophytes, but also those identified from cycad roots (Costa et al. 1999, 2004) and freeliving colonies (Wright et al. 2001). The results showed that most Nostoc trnL genotypes were clearly distinguished from those of other nostocalean genera. Three main sequence types, the Muscorum-, Commune- and Punctiformis-type, were delimited from the main cluster of Nostoc intron sequences. All sequences amplified from lichens had so far belonged to the latter two types. It was also noted that the sampling of $16 \mathrm{~S}$ rRNA genes had been seriously skewed towards Nostoc genotypes with Punctiformis- 
type trnL sequences. This drew into question whether all relevant subgroups of symbiotic Nostoc had been adequately sampled when constructing $16 \mathrm{~S}$ rDNA trees. It was concluded that while the sequence types offered only a heuristic classification, they were not in conflict with phylogenetic divisions based on the 16S rRNA gene and conserved parts of the trnL intron. Furthermore, the identified groups seemed to broadly correspond with some botanical species within the genus Nostoc, which have been characterized on the basis of morphological characters and life-history traits. The findings confirmed that while informative sites in the conserved parts of cyanobacterial trnL sequences were useful for distinguishing between different genera and distantly related Nostoc species, characteristics of the P6b region could only be used for comparing closely related genotypes. In other words, the conspicuous features of this region, such as the presence of one of two contrasting heptanucleotide repeat motifs, was indicative of close phylogenetic relationship only if other shared signature characteristics in the more conserved parts of the intron sequence also indicated that the genotypes were closely related.

Oksanen, Jokela et al. (2004) reported that one Nostoc strain isolated from the bipartite cyanolichen Pannaria pezizoides (Fig. 3G) collected from southern Finland produced six different microcystins in culture. Microcystins are hepatotoxic cyclic heptapeptides which had previously been almost exclusively reported from planktonic cyanobacteria. The presence of the microcystin synthetase gene complex in the Nostoc strain was confirmed by sequencing and the gene sequences were compared of other microcystin-producing cyanobacteria. The phylogenetic position of the toxin-producing Nostoc strain among lichen symbiotic and other cyanobacteria was determined on the basis of full length $16 \mathrm{~S}$ rDNA sequences. This dataset was largely the same as had been previously used for studying the utility of trnL sequences as a phylogenetic marker. The results showed that the toxin-producing Nostoc strain belonged to a monophyletic group of symbiotic Nostoc genotypes, which also included the reference strain $N$. punctiforme PCC 73102 (originally isolated from the cycad Macrozamia in Australia). Among all available Nostoc $16 \mathrm{~S}$ rDNA sequences, the closest relative was another laboratory strain originally isolated from an unspecified lichen species in Scotland.

Svenning et al. (2005) studied the phylogeny of symbiotic and free-living Nostoc strains on the basis of full length $16 \mathrm{~S}$ rDNA sequences. Their sampling included a selection of nostocalean cyanobacteria with an emphasis on symbiotic Nostoc strains isolated from the rhizomes of the angiosperm genus Gunnera (Fig. 6F). An enlarged dataset also included sequences of many Nostoc genotypes identified from lichen symbioses. The results were congruent with earlier findings. All the Nostoc genotypes obtained from Peltigera guild lichens by Rikkinen et al. (2002) fell into one well supported group. This monophyletic group included both free-living and symbiotic Nostoc strains from many different environments. While none of the new sequences were included in the previously described group of Nostoc symbionts from Nephroma guild lichens, also this group was recovered in the extended analysis with strong support. On a general level, the results illustrated a mix of cyanobacteria named as Nostoc within the genus Anabaena and vice versa. The authors discussed this problem and pointed 

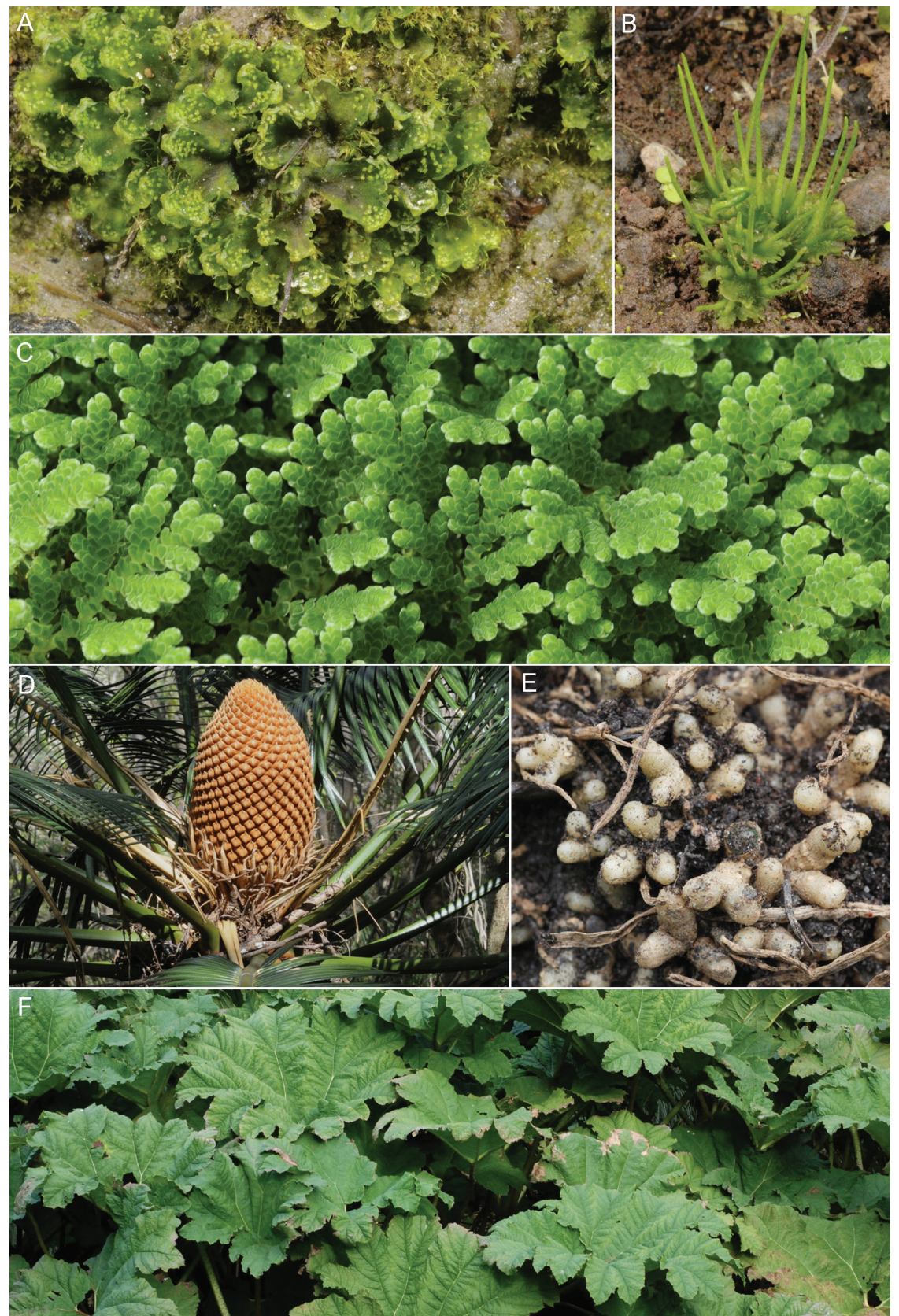

Figure 6. Plant hosts of symbiotic cyanobacteria; some of which can share Nostoc symbionts with cyanolichens. A The liverwort Blasia pusilla has Nostoc symbionts in auricles (Rikkinen and Virtanen 2008) B Hornworts house Nostoc symbionts in slime cavities (Costa et al. 2002) C The cyanobacterial symbiont of the water fern Azolla is not closely related to lichen symbiotic cyanobacteria (Ran et al. 2010) D All cycads associate with cyanobacteria, mainly Nostoc (Costa et al. 1999) E The cyanobacterial symbionts of cycads are housed in specialized roots (Costa et al. 2004, Gehringer et al. 2010, Yamada et al. 2012) F Gunnera species have endosymbiotic Nostoc in creeping rhizomes (Nilsson et al. 2000). 
out that there were several candidate clades to which the genus name Nostoc could be attached. They also suggested their favorite - a well-supported clade including both major groups of lichen symbionts identified in Rikkinen et al. (2002), in addition to related symbiotic and free-living genotypes.

O'Brien et al. (2005) used phylogenetic analyses of partial $16 \mathrm{~S}$ rDNA, rbcLX, and trnL sequences to study the degree of host specialization of Nostoc genotypes associated with four closely related species of Peltigera, and to compare their symbionts with cyanobacteria associated with other lichens and plant hosts, as well as free-living strains of Nostoc and related cyanobacteria. The sequences were obtained from five to seven specimens each of Peltigera canina, P. didactyla, P. membranacea, and P. rufescens, numerous other cyanolichens, and from cyanobacterial isolates from environmental samples, thalloid bryophytes, cycads, Gunnera, and Geosiphon pyriforme. The lichen specimens were mainly from North America and Europe, with smaller sets from other parts of the world. The results were broadly in line with those of earlier studies. The genus Nostoc, as presently circumscribed, comprised two divergent lineages, one with several laboratory strains, and the second with many symbiotic genotypes intermixed with free-living strains from environmental samples. A clade of Nostoc symbionts corresponding to those generally found in Nephroma guild lichens was recovered in all three analyses. The cyanobacteria of individual Peltigera species were often more closely related to Nostoc genotypes identified from other lichen species, plant hosts and/or environmental samples than to each other. This indicated that host specialization among symbiotic Nostoc genotypes was low, and that opportunities for coevolution with different partners appeared to have been rare. There were several cases of Nostoc genotypes from different continents having identical sequences at one or two loci, but cyanobacteria sharing identical genotypes at all three loci were always from the same continent, suggesting that there was some population differentiation at intercontinental scales.

The phylogenetic position of the Pacific North American endemic cyanolichen, Nephroma occultum was analyzed by Piercey-Normore et al. (2006), who identified Nostoc symbionts from two thalli collected from British Columbia. Also the symbiont of a Nephroma isidiosum thallus from the same region was studied. Even though $N$. occultum is endemic to moist forests in western North America, it fell into the same clade with South American temperate rainforest species. The two closely related Nostoc trnL genotypes identified were novel but belonged to the same group of symbionts as that of $N$. isidiosum, and those previously identified from many other Nephroma guild lichens. The authors proposed that a bottleneck that limited genetic variation in the Nostoc photobiont could in part account for the endemism and the decline of N. occultum, and pointed out that a larger number of populations should be analyzed to shed more light on variation in cyanobacterial composition and the possibility of a genetic bottleneck in the Nostoc symbionts.

Stenroos et al. (2006) studied the phylogeny of symbiotic and free-living Nostoc strains on the basis of partial $16 \mathrm{~S}$ rDNA, rbcLX, and trnL sequences. Their sampling included a wide selection of lichen symbiotic and free-living cyanobacteria, with many new sequences from South American specimens of Pseudocyphellaria (Fig. 3B). Data- 
sets from the different gene loci were combined into a single analysis using direct optimisation. The results generally confirmed findings made in earlier studies: many lichen hosts appeared to be strongly selective towards their cyanobionts, while others were generalists, being able to associate with a spectrum of different Nostoc genotypes. Free-living and plant-associated Nostoc genotypes were not clearly separated from the lichen symbiotic ones, and also this analysis confirmed the existence of the distinct lineage of Nostoc genotypes that are typically found in Nephroma guild lichens (now referred to as the Pseudocyphellaria group). In the discussion, the authors interpreted the apparent lack of parallel cladogenesis between different hosts and Nostoc symbionts as evidence of no co-evolution between the symbiotic partners. They also reviewed previous finding regarding the difficulties of using trnL sequences in phylogenetic analysis, and argued that their study was the first one to prove cyanobiont selectivity in lichens.

Studies on the cyanobacterial diversity of Pseudocyphellaria (Fig. 3B) were continued by Summerfield et al. (2006) who identified Nostoc trnL genotypes from several specimens of P. crocata (New Zealand, Australia, Chile, and British Columbia), P. neglecta (New Zealand and Australia), and P. perpetua (British Columbia). Five different Nostoc genotypes were found from the lichens analyzed, two of these in a number of specimens, and three each from a single lichen thallus. Signature characteristics in the trnL sequences show that all these genotypes were Nephroma guild cyanobionts. As no connection was found between genetic diversity of the fungal hosts and symbiont choice, all three Pseudocyphellaria taxa seemed to rely on a common pool of cyanobionts.

Myllys et al. (2007) examined cyanobiont selectivity in eight epiphytic cyanolichen species, two of these tripartite lichens (Lobaria pulmonaria, Peltigera leucophlebia) and the other five bipartite lichens (Nephroma bellum, N. parile, N. resupinatum, Parmeliella triptophylla, Peltigera praetextata). The sampling focused on one old-growth forest in southern Finland, and phylogenetic relationships between cyanobacterial symbionts were analyzed using partial $16 \mathrm{~S}$ rDNA and rbcLX sequences and direct optimisation. The results were again in line with those of earlier studies: two clades of Nostoc symbionts, corresponding to Nephroma guild symbionts (here named Cade II) and Peltigera guild symbionts (here named Clade I), were recovered in all phylogenetic trees. The latter group also included free-living and plant symbiotic Nostoc strains. Within these two main lineages each lichen species associated with only one subclade of Nostoc symbionts, indicating that the fungi were discriminative in their choice of cyanobionts. The main exception was Lobaria pulmonaria (Fig. 3A), which seemed to associate with a wide range of different Nostoc genotypes. Nostoc symbionts exhibited a much lower degree of selectivity towards their fungal partners, and the lichen associations as a whole could not be described as highly specific. The authors found evidence of cyanobiont sharing between several lichen species and also noted that different Nostoc genotypes were present in different Peltigera leucophlebia specimens.

Elvebakk et al. (2008) focused on phylogenetic patterns among Nostoc cyanobionts within bi- and tripartite lichens of the genus Pannaria. The study was based on full length 16S rRNA gene sequences amplified from specimens of 21 Pannaria species collected in seven countries in the northern and northern hemispheres. Also two 
specimens of Pseudocyphellaria from the Juan Fernández Islands were studied. The new Nostoc genotypes were compared to those previously found from various other symbioses and environmental samples. The results showed that while only one Nostoc genotype was present in all bipartite Pannaria thalli, several specimens of tripartite lichens had different Nostoc genotypes in different cephalodia. All the newly identified Nostoc genotypes belonged to one well supported lineage, with the phylogenetic tree showing a gradual transition from the lowermost nodes, corresponding to Nostoc genotypes of the Peltigera guild, to the uppermost, corresponding to Nostoc genotypes of the Nephroma guild. Several subgroups within the major branches gained good support and the Pannaria cyanobionts were placed into three relatively well defined groups. Some bipartite and tripartite lichen species seemed to share similar Nephroma guild symbionts, while other groups of Nostoc genotypes were exclusively found from either bi- or tripartite Pannaria species. After a detailed discussion of the observed diversity patterns the author concluded that while the distributions of some symbiotic Nostoc genotypes were correlated with mycobiont taxonomy at the species or genus level, the distribution patterns of others were best explained by habitat ecology. They also identified two possible cases of coevolution between symbiotic partners.

Papaefthimiou et al. (2008) compared phylogeny and morphology of cyanobacteria originating from different plant symbioses (Anthoceros, Azolla, several cycads, and Gunnera) with free-living Nostoc isolates from different habitats (Fig. 6). While their analysis did not include any cyanobacterial isolates from lichens, some of the plant symbionts included were very closely related to lichen symbiotic strains. The phylogenetic analysis indicated that two distinct patterns of evolution of symbiotic behavior existed within nostocacean cyanobacteria, one leading to the symbioses of Nostoc species with a variety of plants (and lichen-forming fungi), and the other leading to the association of a unique cyanobacterial taxon with the water fern Azolla. The authors suggested that the frequent occurrence of symbiotic strains within Nostoc s.str. would be linked to the intensive hormogonia production that was observed in many of the strains studied.

Rikkinen and Virtanen (2008) returned to Nostoc diversity in thalloid liverworts by identifying cyanobacteria associated with Blasia pusilla (Fig. 6A) in Finland and Cavicularia densa in Japan. The focus was on Nostoc trnL genotypes isolated from vegetative propagules, since both bryophytes studied could promote the persistence of their symbiosis with specialized gemmae, which facilitate the simultaneous dispersal of both symbiotic partners. The results showed that the predominant Nostoc trnL genotypes identified from both bryophytes were closely related and also closely related to those that had been identified from hornworts, cycads and many terricolous cyanolichens. For example, one Nostoc trnL genotype found from B. pusilla in Finland had previously been found from Peltigera occidentalis in western North America. Another genotype had been identified from Peltigera degenii (Canada), P. canina (Germany), P. neopolydactyla (Oregon), P. praetextata (Finland), and P. membranacea (Sweden, Canada, and Oregon). Within this context, Rikkinen (2009) gave a short summary of Nostoc diversity patterns in lichens and argued that symbiont-switches between lichen-forming fungi and plant hosts may have played a role in the evolution of some extant cyanobacterial symbioses. 
Kaasalainen et al. (2009) studied cyanobacterial diversity in Peltigera leucophlebia and confirmed the presence of a microcystin-producing Nostoc strain in the cephalodia of this tripartite lichen species. Cyanobacteria were identified on the basis of full length $16 \mathrm{~S} \mathrm{rDNA}$ sequences and also the presence of the microcystin synthetase gene mcyE was confirmed. A wide variety of different Nostoc $16 \mathrm{~S}$ rRNA genotypes were detected from lichen cephalodia, but only one was found in toxin-producing cultures. In phylogenetic analysis, most Nostoc genotypes from the lichen specimen were placed into three closely related groups among sequences previously obtained from various Peltigera guild lichens and plant symbioses. The closest relatives of the microcystinproducing genotype were the toxin-producing Nostoc strain previously isolated from Protopannaria pezizoides and related Nostoc genotypes from the liverwort Blasia pusilla. It was concluded that the wide diversity of Nostoc genotypes observed may have been partly due to the sampling method used. In order to get enough biomass for chemical analysis, hundreds of minute cephalodia from the upper surface of the lichen had to be pooled into one sample. While it is thus possible that some of the Nostoc genotypes identified might have been epiphytes from the thallus surface, such cyanobacteria could not have produced the high concentration of microcystins detected. Furthermore, all nine Nostoc strains isolated from P. leucophlebia cephalodia produced microcystins in culture and belonged to the one genotype that was dominant among those identified directly from cephalodia.

The taxonomic and geographic scope of earlier studies was expanded by Lücking et al. (2009) who investigated the phylogenetic relationships of presumed Scytonema and Chroococcus cyanobionts in tropical lichen species collected from Costa Rica (Figs 3H, 5D). The study was based of partial $16 \mathrm{~S}$ rDNA sequences. The fungal hosts included both Ascomycota (Coccocarpia) and Basidiomycota (Acantholichen, Dictyonema), and the symbionts were compared with those isolated from several cyanobacterial genera. The results demonstrated that the filamentous or nearly unicellular cyanobacteria of all lichens studied belonged to the same phylogenetic lineage. However, they did not group together with Scytonema isolates, but rather represented a previously unrecognized lineage of lichen symbionts corresponding to the botanical name Rhizonema. The novel lineage was found to be present in at least twelve species and four genera of lichen- forming fungi representing a wide range of morphological variation and systematic affinities. The results also suggested that many Rhizonema genotypes were not host specific, but appeared to have evolved through wide photobiont sharing between unrelated but ecologically similar fungi, i.e. within a photobiont-mediated guild. While discussing specificity and selectivity patterns in lichens the authors noted that the apparent selection of well adopted photobiont strains and subsequent horizontal transfer between unrelated fungi was a phenomenon not very unlike crop domestication in human civilizations.

Otalora et al. (2010) presented a phylogenetic study based on new Nostoc rbcLXS sequences from 24 species of gelatinous cyanolichens of the Collemataceae and many Nostoc sequences obtained in earlier studies (Figs 3E-F). The results showed that there were two contrasting patterns of specificity between collemataceous fungi and Nos- 
toc. The first corresponded to the commonly observed situation for lichens where a monophyletic group of cyanobacteria associated with multiple species of lichen-forming fungi, and where individual fungal species associated with multiple photobiont genotype groups. However, five species of Leptogium and Collema exhibited a different pattern where each monophyletic Nostoc genotype group was associated with only one species of lichen-forming fungus, and this fungus only associated with that unique Nostoc group, indicating strong reciprocal specificity by both symbiotic partners. The five lichen species had in common a largely asexual mode of reproduction where the symbiotic propagules contain both symbionts, allowing a vertical transmission of the photobiont from one fungal generation to the next. All these species also appeared to have specialized to live in relatively narrow ecological niches. The authors concluded that each of the five distinct monophyletic Nostoc groups, associated with the five specific mycobiont species, seemed to represent independent transitions from a generalist state during the evolution of both partners. The transitions might be explained by shifts to asexual fungal reproduction, involving vertical symbiont transmission, and narrowing of ecological niches.

Fedrowitz et al. (2011) studied the diversity patterns of Nostoc trnL genotypes in three epiphytic Nephroma species within a boreal forest landscape in Finland (Fig. 5B). Cyanobacterial 16S rRNA gene sequences were also amplified from a subset of lichen specimens and the fungal ITS gene was used to confirm fungal species identities of critical lichen specimens. The results indicated high photobiont specificity and selectivity within the local forest landscape: only five closely related Nostoc trnL genotypes were identified from the 232 Nephroma thalli analyzed. Two Nostoc genotypes were widely shared by $N$. bellum and $N$. resupinatum, while the thalli of $N$. parile always contained one of two different genotypes. On individual tree trunks all thalli of each Nephroma species usually contained the same Nostoc genotype. Furthermore, the two lichen species that mainly disperse via fungal spores ( $N$. bellum and $N$. resupinatum) tended to have identical photobionts, while the symbiotically dispersing $N$. parile clearly relied on its own symbiont pool. On a landscape level, the distribution of all Nostoc genotypes seemed to have been influenced by strong founder effects presumably caused by relatively low colonization rates from one tree to another.

Fedrowitz et al. (2012) continued studies on the spatial aspects of symbiont specificity in Nephroma by examining the genetic diversity of fungal hosts and associated Nostoc photobionts within a global framework. The data set consisted of 271 Nephroma ITS sequences and 358 Nostoc trnL intron sequences, with over 150 sequence pairs originating from single lichen thalli. The results reconfirmed that all bipartite Nephroma species associate with one group of Nostoc different from the cyanobacterial symbionts found in cephalodia of tripartite Nephroma species. Most bipartite Nephroma species shared their Nostoc symbionts with at least one other species, and none of them associated with a single Nostoc genotype, generally supporting the existence of wide symbiont sharing. While the existence of specific associations between some symbiont pairs could be observed over vast geographical distances, genetic differences in both groups of symbionts tended to increase with increasing geographical distance. It 
was concluded that symbiont selectivity patterns among the Nephroma species studied were best described as a geographic mosaic, with higher selectivity locally than globally. This mosaic of symbiotic interactions probably partly reflects regional coadaptation of specific symbiont combinations to particular environmental conditions, but also the influence of random effects during dispersal history.

The structural evolution in the P6b region of trnL sequences was studied further by Olsson et al. (2012). All the analyzed sequences were amplified from the monophyletic group of lichen symbiotic Nostoc that characterizes all lichens of the Nephroma guild. Phylogenetic analyses of $16 \mathrm{rDNA}$ and trnL intron sequences, and secondary structure reconstructions of transcribed P6b stem loops were used to study the replication mechanisms and to gain new insights into distribution of indels not corresponding to the typical tandem repeat motif of these sequences. The results indicated that indel events were usually accompanied by specific single nucleotide changes in the P6b region and had occurred several times independently. In spite of this, the P6b sequences were found to provide useful phylogenetic information within this group of closely related Nostoc genotypes. Elhai et al. (2008) had previously reported that the short segments of non-repeating DNA interrupting the tandem repeats of trnL introns are dispersed throughout cyanobacterial genomes. The analyses of such sequences in context with their surroundings gave new information of the possible mechanistic basis of their dispersal, apparently distinct from mechanisms thus far described.

Finally, Kaasalainen et al. (2012) identified microcystin-producing cyanobacteria from cyanolichens by amplifying a part of the gene cluster encoding the enzyme complex responsible for toxin production and detecting the compounds directly from lichen thalli. The data set included 803 cyanolichen specimens originating from five different continents. Also cyanobacterial $16 \mathrm{~S}$ rRNA sequences were obtained from all toxin producing thalli. The results showed that lichens with cyanobacterial toxins are common and found all over the globe. The cyanobacterial mcyE gene was amplified from nearly a hundred lichen specimens. Thirty different mcyE gene sequences were identified and these grouped together with the mcyE genes previously sequenced from other heterocystous cyanobacteria. 41 Nostoc $16 \mathrm{~S}$ rDNA genotypes were found from the same set of specimens, always only one genotype from each lichen specimen. The phylogenetic trees constructed using mcyE and $16 \mathrm{~S}$ rDNA sequences were not congruent, but both displayed a similar sporadic distribution of toxin-producing Nostoc symbionts among different cyanolichen groups and geographical origins. It was proposed that from an evolutionary perspective the high diversity of mcyE genes in lichen symbiotic cyanobacteria would be partly explained by their symbiotic way of life, especially the packaging of cyanobacterial symbionts into small vertically transmitted populations that must be relatively prone to random events, disruptive selection and genetic drift. In other words, when compartmentalized into the symbiotic propagules, the Nostoc symbionts invariably experience genetic bottlenecks where population sizes are severely reduced. At the same time, the symbiotic association with a fungal host may favor different chemical traits from those typically seen in many free-living Nostoc. The recurrent bottlenecks and other population shaping effects may thus account 
for the high genetic and chemical diversity observed. Concurrently, lichen symbioses may have been an important environment for the diversification of toxin-producing cyanobacteria.

In addition to the primary research articles reviewed above, relevant discussions concerning the genetic diversity of lichen symbiotic cyanobacteria have also been published in several PhD theses, including those of Per Paulsrud (2002), Ilona Oksanen (2004) and Katja Fedrowitz (2011).

\section{Conclusions and future perspectives}

Per Paulsrud and Peter Lindblad (1998) ended their pioneering study on the diversity of lichen symbiotic Nostoc with the following words. "This study is the first step in a more extensive survey of the genetic diversity of symbiotic cyanobacteria. We have addressed several important questions concerning lichen biology and presented a method which opens up the possibility of studying these, and other, symbiotic systems in more detail. Examining other symbiotic systems by the same approach will not only provide information concerning the biology of these systems but will also reveal similarities and differences between cyanobacterial symbioses in general."

Now, fifteen years and many interesting steps later, we are still only beginning to understand the complex network of biological interactions and evolutionary processes in which symbiotic cyanobacteria and their fungal partners live and diversify. During the coming years we can undoubtedly enjoy the results of many intriguing case studies of cyanobacterial diversity in new taxonomic groups and in different ecological settings. The genetic diversity of several important lineages of lichen symbiotic cyanobacteria remains totally unknown and the same applies to many biomes rich in cyanolichen species. When will we see the first in-depth studies on the cyanobacterial symbionts of Lichinomycetes, and on the hyperdiverse cyanolichen communities of tropical montane rainforests, for example?

Three different loci have so far been used in molecular studies of lichen symbiotic cyanobacteria: $16 \mathrm{~S}$ rDNA, trnL, and rbcLXS. These markers have been used singly or in combination, and they all have their positive and negative aspects (e.g. Han et al. 2009). For example, the 16S rDNA gene is too conserved for many uses and trnL sequences are difficult to use in phylogenetic analyses. In some cases the different markers have also given partly incongruent results. For example, O’Brien et al. (2005) reported that while DNA extractions from Peltigera degenii and P. horizontalis, respectively, gave identical trnL sequences, there were substantial differences in partial $16 \mathrm{~S}$ rDNA and rbcLX sequences. In two further cases DNA extractions produced identical $16 S$ sequences and similar rbcLX sequences, but trnL intron sequences which had different repeat motifs in the $\mathrm{P} 6 \mathrm{~b}$ region. In eleven pairwise comparisons, the DNA extractions containing identical trnL sequences differed at both other loci and there were five and three comparisons, respectively, where only the $16 \mathrm{~S}$ rDNA or the rbcLX sequences were identical. 
These observations underline the problems one can encounter for example when trying to place a set of Nostoc trnL genotypes from different geographical regions and cyanolichen species into a phylogenetic context. On the other hand, there are also some inherent problems in screening multiple gene loci from complex biological material such as lichen thalli. A square millimetre of lichen may first appear like a small sample, but in the world of bacteria it is relatively huge. Extracts from lichen specimens will commonly contain DNA from thousands of cyanobacterial cells - potentially belonging to several different genotypes, species or even genera. Naturally the desired locus of the dominant DNA is usually amplified, but not necessarily in all cases. This is a particular problem in studies where several different loci are amplified: how can we know for sure that all the loci were amplified from the DNA of the same cyanobacterium? This is one reason why multi-gene analyses from field specimens should eventually be supplemented by data from unialgal laboratory cultures.

All bipartite cyanolichen species studied so far have appeared to house only one cyanobacterial genotype in each thallus. However, attempts to isolate symbionts into culture have often revealed the presence of several different genotypes in the same material. For example, Summerfield et al. (2002) found that Nostoc isolates from three Pseudocyphellaria species were different to those identified directly from lichen thalli, and did not seem to represent the primary symbionts of the lichens. Indeed, attempts to culture the correct symbiont from a lichen thallus can often be confused by the common presence of epiphytic cyanobacteria or their propagules. It will be interesting to see whether further studies will keep reconfirming the dominance of only one symbiont genotype in each bipartite cyanolichen thallus or reveal that also minor symbionts can sometimes be present. The latter option would not be all that surprising in the light of comparable findings from other symbioses, such as green algal lichens (e.g. Casano et al. 2011) and corals (e.g. Silverstein et al. 2012). It is quite feasible that the observed symbiont diversity in some cyanolichen species reflects one mechanism by which these symbioses respond to habitat variability and environmental change: it may allow some fungal hosts to associate with the cyanobacterial genotypes that are optimally adapted to the prevailing conditions. In some cases such processes might well operate on the level of single cyanolichen thalli - especially in the case of cephalodiate species.

Already Paulsrud and Lindblad (1998) noted that in order to determine to what extent fungal hosts really discriminate between Nostoc genotypes, we would need a much better knowledge of the diversity of cyanobacteria in the soil. The almost total lack of information on the diversity of aposymbiotic cyanobacteria in lichen habitats is still a major problem, seriously hindering attempts to understand the dispersal ecology of cyanolichens, among many other questions. The few studies in which cyanobacteria have been cultured from bark and soil have generally revealed high diversity in the substrate (e.g. Rikkinen et al. 2002, Rikkinen and Virtanen 2008). However, the possible connections between free-living cyanobacteria and their lichen symbiotic relatives remain unknown.

Some cases where different cyanobacteria are consistently found from different thalli of single cyanolichen species are explained by previously unrecognized heterogeneity 
within the fungal host. However, in many cases one fungal species can associate with more than one symbiont and these are often also shared by several other cyanolichen species. The concept of photobiont-mediated guilds in lichens gained attention after it was published by Rikkinen et al. (2002) and refined by Rikkinen (2003). However, the basic idea was already presented in Rikkinen (1995) while trying to explain the apparent lack of interspecific competition observed in many lichen communities. As such, the concept has clear roots in the community ecology of the late 1900's (e.g. Hawkins and MacMahon 1989, Simberloff and Dayan 1991, Wilson 1999). While numerous ecological studies have since examined how coevolutionary interactions are modified within ecological communities (e.g. Thrall et al. 2007, Crowley and Cox 2011), the only synthetic theory presented so far is that of Thompson (2005). It is rewarding to see that the author chose to use lichens as an example when describing how, so long as some horizontal transmission of symbionts is possible, geographic mosaics of coevolution tend to produce variable degrees of reciprocal specificity in coevolving mutualistic symbioses.

Finally, it is important to note that molecular studies on the diversity of symbiotic cyanobacteria in lichens have not developed in a vacuum, but in close conceptual interaction with comparable studies on plant symbiotic and non-symbiotic cyanobacteria, lichen-symbiotic green algae, and lichen-forming fungi. Multidisciplinary influences have been crucial and will continue to be so in the future. For example, the recent description of the highly eroded genome of the cyanobacterial symbiont in Azolla (Ran et al. 2010) raises many interesting questions regarding the potential nature of some lichen symbiotic cyanobacteria that have not been successfully isolated into culture. In any case, the new genomic approaches will open many intriguing questions and provide novel approaches for future research.

\section{References}

Besendahl A, Qiu Y-L, Lee J, Palmer JD, Bhattacharya D (2000) The cyanobacterial origin and vertical transmission of the plastid tRNALeu group-I-intron. Current Genetics 37: 12-23. doi: $10.1007 / \mathrm{s} 002940050002$

Bergman B, Hällbom L (1982) Nostoc in Peltigera canina when lichenized and isolated. Canadian Journal of Botany 60: 2092-2098. doi: 10.1139/b82-256

Casano LM, del Campo EM, García-Breijo FJ, Reig-Armiñana J, Gasulla F, Del Hoyo A, Guéra A, Barreno E (2011) Two Trebouxia algae with different physiological performances are everpresent in lichen thalli of Ramalina farinacea. Coexistence versus competition? Environmental Microbiology 13: 806-818. doi: 10.1111/j.1462-2920.2010.02386.x

Costa JL, Paulsrud P, Lindblad P (1999) Cyanobiont diversity within coralloid roots of selected cycad species. FEMS Microbiology Ecology 28: 85-91. doi: 10.1111/j.1574-6941.1999. tb00563.x

Costa JL, Paulsrud P, Lindblad P (2002) The cyanobacterial tRNALeu (UUA) intron: Evolutionary patterns in a genetic marker. Molecular Biology and Evolution 19: 850-857. doi: 10.1093/oxfordjournals.molbev.a004142 
Costa JL, Romero EM, Lindblad P (2004) Sequence based data supports a single Nostoc strain in individual coralloid roots of cycads. FEMS Microbiology Ecology 49: 481-487. doi: 10.1016/j.femsec.2004.05.001

Crowley PH, Cox JJ (2011) Intraguild mutualism. Trends in Ecology and Evolution 26: 627633. doi: 10.1016/j.tree.2011.07.011

Degelius G(1954) The lichen genus Collema in Europe. Symbolae Botanicae Upsalienses 13: 361-382.

Elvebakk A, Papaefthimiou D, Robertsen EH, Liaimer A (2008) Phylogenetic patterns among Nostoc cyanobionts within bi- and tripartite lichens of the genus Pannaria. Journal of Phycology 44: 1049-1059. doi: 10.1111/j.1529-8817.2008.00556.x

Fedrowitz K (2011) Insights into the Ecology and Genetics of Lichens with a Cyanobacterial Photobiont. PhD Thesis, Swedish University of Agricultural Sciences, Sweden.

Fedrowitz K, Kaasalainen U, Rikkinen J (2011) Genotype variability of Nostoc symbionts in three epiphytic Nephroma species in a boreal forest landscape. The Bryologist 114: 220 230. doi: 10.1639/0007-2745-114.1.220

Fedrowitz K, Kaasalainen U, Rikkinen J (2012) Geographic mosaic of symbiont selectivity in a genus of epiphytic cyanolichens. Ecology and Evolution 2: 2291-2303. doi: 10.1002/ece3.343

Feige GB (1978) Physiologische Charakteristika der Heterocystendifferenzierung in verschiedenen Blaualgenflechten. Berichte der Deutschen Botanischen Geselschaft 91: 595-602.

Forssel KBJ (1883) Studier öfver cephalodierna. Bidrag till kännedomen om lafvarnes anatomi och utvecklingshistoria. Bihang Till Kungliga Svensk Vetensaps-Akademiens Handlingar 8: 1-112.

Gehringer MM, Pengelly JJ, Cuddy WS, Fieker C, Forster PI, Neilan BA (2010) Host selection of symbiotic cyanobacteria in 31 species of the Australian cycad genus: Macrozamia (Zamiaceae). Molecular Plant-Microbe Interactions 23: 811-822. doi: 10.1094/MPMI23-6-0811

Geitler L (1932) Cyanophyceae. In: Rabenhorst L (Ed) Kryptogamen-Flora von Deutschland, Österreich und der Schweiz. Akademische Verlagsgesellschaft, Leipzig, 1056 pp.

Han D, Fan Y, Hu Z (2009) An evaluation of four phylogenetic markers in Nostoc: implications for cyanobacterial phylogenetic studies at the intrageneric level. Current Microbiology 58: 170-176. doi: 10.1007/s00284-008-9302-x

Hawkins CP, MacMahon, JA (1989) Guilds: The multiple meanings of a concept. Annual Review of Entomology 34: 423-451. doi: 10.1146/annurev.en.34.010189.002231

Jordan WP, Rickson FR (1971) Cyanophyte cephalodia in the lichen genus Nephroma. American Journal of Botandy 58: 562-568. doi: 10.2307/2441039

Kaasalainen U, Fewer D, Jokela J, Wahlsten M, Sivonen K, Rikkinen J (2012) Cyanobacteria produce a high variety of hepatotoxic peptides in lichen symbiosis. Proceedings of the National Academy of Sciences of the United States of America 109: 5886-5891. doi: 10.1073/pnas.1200279109

Kaasalainen U, Jokela J, Fewer DP, Sivonen K, Rikkinen J (2009) Microcystin production in the tripartite cyanolichen Peltigera leucophlebia. Molecular Plant-Microbe Interactions 22: 695-702. doi: 10.1094/MPMI-22-6-0695

Kardish N, Kessel M, Galun M (1989) Characterization of symbiotic and cultured Nostoc of the lichen Nephroma laevigatum Ach. Symbiosis 7: 257-266. 
Kardish N, Rotem-Abarbanell D, Ziberstein A, Galun M (1990) Comparison between the symbiotic Nostoc of the lichen Nephroma laevigatum Ach. and its cultured, isolated Nostoc by recombination DNA. Symbiosis 8: 135-145.

Kuhsel MG, Strickland R, Palmer JD (1990) An ancient group I intron shared by eubacteria and chloroplasts. Science 250: 1570-1573. doi: 10.1126/science.2125748

Leizerovich I, Kardish N, Galun M (1990) Comparisons between eight symbiotic, cultured Nostoc isolates and a free-living Nostoc by recombinant DNA. Symbiosis 8: 75-85.

Linke K, Hemmerich J, Lumbsch HT (2003). Identification of Nostoc cyanobionts in some Peltigera species using a group I intron in the $\mathrm{tRNA}^{\text {Leu }}$ gene. - Bibliotheca Lichenologica 86: 113-118.

Lohtander K, Oksanen I, Rikkinen J (2002) A phylogenetic study of Nephroma (lichen-forming Ascomycota). Mycological Research 106: 777-787. doi: 10.1017/S0953756202006068

Lohtander K, Oksanen I, Rikkinen J (2003) Genetic diversity of green algal and cyanobacterial photobionts in Nephroma (Peltigerales). The Lichenologist, 35: 325-339. doi: 10.1016/ S0024-2829(03)00051-3

Lücking R, Lawrey JD, Sikaroodi M, Gillevet PM, Chaves JL, Sipman HJM, Bungartz F (2009) Do lichens domesticate photobionts like farmers domesticate crops? Evidence from previously unrecognized lineage of filamentous cyanobacteria. American Journal of Botany 96: 1409-1418. doi: 10.3732/ajb.0800258

Miao VPW, Rabenau A, Lee A (1997) Cultural and molecular characterization of photobionts of Peltigera membranacea. The Lichenologist 29: 571-586. doi: 10.1006/lich.1997.0114

Mollenhauer D (1988) Nostoc species in the field. Archiv für Hydrobiologie, Supplement Volumes 50-53: 315-326.

Myllys L, Stenroos S, Thell A, Kuusinen M (2007) High cyanobiont selectivity of epiphytic lichens in old growth boreal forest of Finland. New Phytologist 173: 621-629. doi: 10.1111/j.1469-8137.2006.01944.x

Nilsson M, Bergman B, Rasmussen U (2000) Cyanobacterial diversity in geographically related and distant host plants of the genus Gunnera. Archives of Microbiology 173: 97-102. doi: $10.1007 /$ s002039900113

O’Brien HE, Miadlikowska J, Lutzoni F (2005) Assessing host specialization in symbiotic cyanobacteria associated with four closely related species of the lichen fungus Peltigera. European Journal of Phycology 40: 363-378. doi: 10.1080/09670260500342647

Oksanen I (2004) Specificity in cyanobacterial lichen symbiosis and bioactive metabolites (ethylene and microcystins). PhD Thesis, University of Helsinki, Finland.

Oksanen I, Jokela J, Fewer DP, Wahlsten M, Rikkinen J, Sivonen K (2004) Discovery of rare and highly toxic microcystins from lichen-associated cyanobacterium Nostoc sp. strain IO-102-I. Applied and Environmental Microbiology 70: 5756-5763. doi: 10.1128/ AEM.70.10.5756-5763.2004

Oksanen I, Lohtander K, Paulsrud P, Rikkinen J (2002) A molecular approach to cyanobacterial diversity in a rock-pool community involving gelatinous lichens and free-living Nostoc colonies. Annales Botanici Fennici 39: 93-99.

Oksanen I, Lohtander K, Sivonen K, Rikkinen J (2004) Repeat-type distribution in trnL intron does not correspond with species phylogeny: comparison on the genetic markers $16 \mathrm{~S}$ 
rRNA and trnL intron in heterocystous cyanobacteria. International Journal of Systematic and Evolutionary Microbiology 54: 765-772. doi: 10.1099/ijs.0.02928-0

Olsson S, Kaasalainen U, Rikkinen J (2012) Reconstruction of structural evolution in the trnL intron P6b loop of symbiotic Nostoc (Cyanobacteria). Current Genetics 58: 49-58. doi: 10.1007/s00294-011-0364-0

Otalora MAG, Martinez I, O’Brien H, Molina MC, Aragon G, Lutzoni F (2010) Multiple origins of high reciprocal specificity at an intercontinental spatial scale among gelatinous lichens (Collemataceae, Lecanoromycetes). Molecular Phylogenetics and Evolution 56: 1089-1095. doi: 10.1016/j.ympev.2010.05.013

Papaefthimiou D, Hrouzek P, Mugnai MA, Lukesova A, Turicchia S, Rasmussen U, Ventura S (2008) Differential patterns of evolution and distribution of the symbiotic behaviour in nostocacean cyanobacteria. International Journal of Systematic and Evolutionary Microbiology 58: 553-564. doi: 10.1099/ijs.0.65312-0

Paquin B, Kathe SD, Nierzwicki-Bauer SA, Shub DA (1997) Origin and evolution of group I introns in cyanobacterial tRNA genes. Journal of Bacteriology 179: 6798-6806.

Paulsrud P (2002) The Nostoc symbiont of lichens: diversity, specificity and cellular modifications. PhD Thesis, Uppsala University, Sweden.

Paulsrud P, Lindblad P (1998) Sequence variation of the tRNALeu intron as a marker for genetic diversity and specificity of symbiotic cyanobacteria in some lichens. Applied and Environmental Microbiology 64: 310-315.

Paulsrud P, Rikkinen J, Lindblad P (1998) Cyanobiont specificity in some Nostoc-containing lichens and in a Peltigera aphthosa photosymbiodeme. New Phytologist 139: 517-524. doi: 10.1046/j.1469-8137.1998.00220.x

Paulsrud P, Rikkinen J, Lindblad P (2000) Spatial patterns of photobiont diversity in some Nostoc-containing lichens. New Phytologist 146: 291-299. doi: 10.1046/j.14698137.2000.00647.x

Paulsrud P, Rikkinen J, Lindblad P (2001) Field investigations on cyanobacterial specificity in Peltigera aphthosa. New Phytologist 152: 117-123. doi: 10.1046/j.0028646x.2001.00234.x

Piercey-Normore MD, Coxson D, Goward T, Goffinet B (2006) Phylogenetic position of a Pacific North American endemic cyanolichen, Nephroma occultum (Ascomycota, Peltigerales). The Lichenologist 38: 441-456. doi: 10.1017/S0024282906005950

Ran L, Larsson J, Vigil-Stenman T, Nylander JA, Ininbergs K, Zheng WW, Lapidus A, Lowry S, Haselkorn R, Bergman B (2010) Genome erosion in nitrogen-fixing vertically transmitted endosymbiotic multicellular cyanobacterium. PLoS One 5: e11486. doi: 10.1371/ journal.pone.0011486

Rikkinen J (1995) What's behind the pretty colours? A study on the photobiology of lichens. Bryobrothera 4: 1-239.

Rikkinen J (2002) Cyanolichens: An evolutionary overview. In Rai AN, Bergman B, Rasmussen U (eds) Cyanobacteria in Symbiosis. Kluwer Academic Publisher, Dordrecht, pp. 31-72.

Rikkinen J (2003) Ecological and evolutionary role of photobiont-mediated guilds in lichens. Symbiosis 34: 99-110. 
Rikkinen J (2004) Ordination analysis of tRNALeu (UAA) intron sequences in lichen-forming Nostoc strains and other cyanobacteria. Symbolae Botanicae Upsalienses 34: 377-391.

Rikkinen J (2009) Relations between cyanobacterial symbionts in lichens and plants. In Pawlowski K (ed) Prokaryotic Symbionts in Plants, Microbiology Monographs 8, Springer Verlag, Berlin Heidelberg, 265-270.

Rikkinen J, Oksanen I, Lohtander K (2002) Lichen guilds share related cyanobacterial symbionts. Science 297: 357. doi: 10.1126/science.1072961

Rikkinen J, Virtanen V (2008) Genetic diversity in cyanobacterial symbionts of thalloid bryophytes. Journal of Experimental Botany 59: 1013-1021. doi: 10.1093/jxb/ern003

Rudi K, Fossheim T, Jakobsen KS (2002) Nested evolution of a tRNA ${ }^{\text {Leu }}$ (UAA) group I intron by both horizontal intron transfer and recombination of the entire tRNA locus. Journal of Bacteriology 184: 666-671. doi: 10.1128/JB.184.3.666-671.2002

Rudi K, Jakobsen KS (1997) Cyanobacterial tRNA ${ }^{\text {Leu }}$ (UAA) group I introns have polyphyletic origin. FEMS Microbiology Letters 156: 293-298. doi: 10.1111/j.1574-6968.1997. tb12743.x

Rudi K, Jakobsen KS (1999) Complex evolutionary patterns of tRNALeu (UAA) group I introns in the cyanobacterial radiation. Journal of Bacteriology 181: 3445-3451.

Silverstein RN, Correra AMS, Baker AC (2012) Specificity is rarely absolute in coral-algal symbiosis: implications for coral response to climate change. Proceedings of the Royal Society B 279: 2609-2618. doi: 10.1098/rspb.2012.0055

Simberloff D, Dayan T (1991) The guild concept and the structure of ecological communities. Annual Review of Ecology and Systematics 22: 115-143. doi: 10.1146/annurev. es.22.110191.000555

Stenroos S, Högnabba L, Myllys L, Hyvönen J, Thell A (2006) High selectivity in cyanobacterial associations of lichenized ascomycetes and cyanobacteria. Cladistics 22: 230-238. doi: 10.1111/j.1096-0031.2006.00101.x

Summerfield TC, Galloway DJ, Eaton-Rye JJ (2002) Species of cyanolichens from Pseudocyphellaria with indistinguishable ITS sequences have different photobionts. New Phytologist 155: 121-129. doi: 10.1046/j.1469-8137.2002.00431.x

Summerfield TC, Eaton-Rye JJ (2006) Pseudocyphellaria crocata, P. neglecta and P. perpetua from the Northern and Southern Hemispheres are a phylogenetic species and share cyanobionts. New Phytologist 170: 597-607. doi: 10.1111/j.1469-8137.2006.01701.x

Svenning MM, Eriksson T, Rasmussen U (2005) Phylogeny of symbiotic cyanobacteria within the genus Nostoc based on $16 S$ rDNA analyses. Archives of Microbiology 183: 19-26. doi: 10.1007/s00203-004-0740-y

Thompson JN (2005) The Geographic Mosaic of Coevolution. University of Chicago Press, Chicago, 443 pp.

Thrall PH, Hochberg ME, Burdon JJ, Bever JD (2007) Coevolution of symbiotic mutualists and parasites in a community context. Trends in Ecology and Evolution 22: 120-126. doi: 10.1016/j.tree.2006.11.007

Tschermak-Woess E (1988) The algal partner. In: Galun M (Ed.) CRC Handbook of Lichenology. Volume I. CRC Press Inc., Boca Raton, 39-92. 
Wilson JB (1999) Guilds, functional types and ecological groups. Oikos 86:507-522. doi: $10.2307 / 3546655$

Wirtz N, Lumbsch T, Green TGA, Turk R, Pintado A, Sancho L, Schroeter B (2003) Lichen fungi have low cyanobiont selectivity in maritime Antarctica. New Phytologisst 160:177-183. doi: 10.1046/j.1469-8137.2003.00859.x

Wright D, Prickett T, Helm RF, Potts M (2001) Form species Nostoc commune (Cyanobacteria). International Journal of Systematic and Evolutionary Microbiology 51:1839-1852. doi: 10.1099/00207713-51-5-1839

Xu MQ, Kathe SD, Goodrichblair H, Nierzwicki-Bauer SA, Shub DA (1990) Bacterial origin of a chloroplast intron - conserved self-splicing group-I introns in cyanobacteria. Science 250:1566-1570. doi: 10.1126/science.2125747

Yamada S, Ohkubo S, Miyashita H, Setoguchi H (2012) Genetic diversity of symbiotic cyanobacteria in Cycas revoluta (Cycadaceae). FEMS Microbiology Ecology 81:696-706. doi: 10.1111/j.1574-6941.2012.01403.x 